www.nature.com/jhg

\title{
New mutations in the GLA gene in Brazilian families with Fabry disease
}

\author{
Lauro Thiago Turaça ${ }^{1,6}$, Juliana Gilbert Pessoa ${ }^{1,6}$, Fabiana Louise Motta ${ }^{1}$, Maria Verônica Muñoz Rojas ${ }^{2}$, \\ Karen Barbosa Müller ${ }^{3}$, Charles Marques Lourenço ${ }^{4}$, Wilson Junior Marques ${ }^{4}$, Vania D’Almeida ${ }^{5}$, Ana Maria \\ Martins $^{3}$ and João Bosco Pesquero ${ }^{1}$
}

Fabry disease (FD) is an X-linked inborn error of glycosphingolipid catabolism that results from mutations in the alphagalactosidase $A(G L A)$ gene. Evaluating the enzymatic activity in male individuals usually performs the diagnosis of the disease, but in female carriers the diagnosis based only on enzyme assays is often inconclusive. In this work, we analyzed 568 individuals from 102 families with suspect of FD. Overall, 51 families presented 38 alterations in the GLA gene, among which 19 were not previously reported in literature. The alterations included 17 missense mutations, 7 nonsense mutations, 7 deletions, 6 insertions and 1 in the splice site. Six alterations (R112C, R118C, R220X, R227X, R342Q and R356W) occurred at $\mathrm{CpG}$ dinucleotides. Five mutations not previously described in the literature (A156D, K237X, A292V, I317S, c.1177_1178insG) were correlated with low GLA enzyme activity and with prediction of molecular damages. From the 13 deletions and insertions, 7 occurred in exons 6 or $7(54 \%)$ and 11 led to the formation of a stop codon. The present study highlights the detection of new genomic alterations in the GLA gene in the Brazilian population, facilitating the selection of patients for recombinant enzyme-replacement trials and offering the possibility to perform prenatal diagnosis.

Journal of Human Genetics (2012) 57, 347-351; doi:10.1038/jhg.2012.32; published online 3 May 2012

Keywords: alpha-galactosidase A; fabry disease; Brazilian families; GLA gene; lysosomal storage disease; mutation analysis

\section{INTRODUCTION}

Fabry disease (FD; MIM 301500) is an X-linked inherited disorder caused by a deficiency of a lysosomal hydrolase, alpha-galactosidase A (GLA; EC3.2.1.22). ${ }^{1}$ Defects in this enzyme leads to progressive accumulation of globotriaosylceramide $\left(\mathrm{Gb}_{3}\right)$ and related glycosphingolipids, primarily in the vascular endothelium, leading to renal failure, cardiac and cerebrovascular disease. ${ }^{1,2}$ The incidence of FD has been estimated to be approximately 1 in 40000 to 1 in 117000 male births. ${ }^{3,4} \mathrm{X}$-linked disorders affect males, whereas the female carriers are generally asymptomatic, owing, at least partially, to the random inactivation of the $\mathrm{X}$ chromosome. ${ }^{5}$ Males with the classic form of FD present the disease onset usually in the first decade of life. Typical clinical manifestations include angiokeratomas, hypohidrosis, pain attacks and various cardiac, renal and/or neurological features, leading ultimately to progressive kidney failure, cardiac insufficiency and stroke. ${ }^{6}$

Enzymatic identification of female carriers of the mutations in Fabry gene is less reliable as heterozygotes can express levels of GLA activity ranging from essentially zero to normal owing to random $\mathrm{X}$-chromosomal inactivation. ${ }^{7}$ Heterozygous females are generally asymptomatic and may have FD as severe as that in males although with progression of disease considerably slower. ${ }^{8,9}$ Then, the only certain method of detecting a female carrier is through molecular analysis. $^{1}$

Disease onset and severity of clinical manifestations depend principally on residual GLA enzymatic activity. Patients with the mild phenotype retain some residual GLA activity, whereas individuals with the severe phenotype tend to show no activity in GLA enzyme assays. The severe phenotype of FD is characterized by severe pain, ocular opacity, skin lesions, liver and kidney dysfunctions and related to the accumulation of GLA substrates in the vascular endothelium. ${ }^{1}$ The mild phenotype of FD tends to show symptoms restricted to cardiac abnormalities. Thus, further collections of mutation data are important to provide insights concerning genotype and phenotype correlation.

Clinical trials and post-approval medical prescription of GLA replacement therapy have indicated the safety and efficacy for patients with the classical phenotype. ${ }^{10-12}$ Then, identification of mutations for FD diagnosis is very important for early therapeutic intervention.

The GLA gene spans $12 \mathrm{~kb}$ and is divided into seven exons; ${ }^{13,14}$ the cDNA encodes a polypeptide of 429 amino acids including a

${ }^{1}$ Department of Biophysics, Universidade Federal de Sao Paulo, São Paulo, Brazil; ${ }^{2}$ Personalized Genetic Health, Genzyme do Brasil, São Paulo, Brazil; ${ }^{3}$ Department of Pediatrics, Universidade Federal de Sao Paulo, São Paulo, Brazil; ${ }^{4}$ Departament of Neuroscience, Faculdade de Medicina de Ribeirao Preto, Hospital das Clínicas de Ribeirao Preto, Universidade de Sao Paulo; São Paulo, Brazil and ${ }^{5}$ Department of Psychobiology, Universidade Federal de Sao Paulo, São Paulo, Brazil

6These authors contributed equally to this work

Correspondence: Professor JB Pesquero, Department of Biophysics, Universidade Federal de Sao Paulo, Rua Pedro de Toledo 669, Sao Paulo 04039-032, Brazil. E-mail: jbpesquero@unifesp.br

Received 1 November 2011; revised 29 January 2012; accepted 6 March 2012; published online 3 May 2012 
31-residue leader sequence. ${ }^{15,16}$ Over 600 mutations in the GLA gene have been described so far in the Human Gene Mutation Database (http://www.hgmd.org). The mutations include missense, nonsense and splice-site mutations, and partial gene rearrangements, including small and large intragenic deletions and insertions.

In this study, 102 Brazilian families with 568 individuals with suspect of FD were analyzed and 222 patients had alterations in the GLA gene. All male patients who had their GLA gene sequenced were previously submitted to clinical and enzyme activity analysis. All the patients had at least one Fabry symptom (angiokeratomas, hypohidrosis, pain attacks, cardiac, renal and/or neurological features) and presented an enzyme activity value near or below the cutoff. The female patients were only submitted to the clinical evaluation and showed at least one Fabry symptom. In all, 38 alterations have been found, among which 19 were not described in the literature. The alterations included 17 missense mutations, 7 nonsense mutations, 7 deletions, 6 insertions and 1 mutation in splice site.

The identification of mutations in patients and the study of new genomic alterations are extremely important for diagnosis and genetic counseling. In addition, it offers the possibility to perform prenatal diagnosis and facilitates the selection of patients for recombinant enzyme-replacement trials.

\section{MATERIALS AND METHODS}

\section{Blood sampling and isolation of genomic DNA}

Peripheral blood from 568 individuals of both genders susceptible for FD was collected in tubes containing ethylene diamine tetraacetate (EDTA) for DNA extraction. Research protocols and consent forms were approved by the Medical Research and Ethical Committee of Universidade Federal de São Paulo (0585/07). Genomic DNA was extracted from total blood using illustra blood genomicPrep mini Spin Kit (GE Healthcare UK Ltd, Buckinghamshire, UK) according to manufacturer's conditions.

\section{PCR}

The amplification of the genomic DNA was achieved by using PCR with the TopTaq Master Mix Kit (QIAGEN, Melbourne, Victoria, Australia) according to manufacturer's conditions. Sense and anti-sense oligonucleotide primers were synthesized based on the sequences flanking the 7 exons of the GLA gene, as shown in Table 1. The PCR conditions were: $94^{\circ} \mathrm{C}$ for $5 \mathrm{~min}$, followed by $94{ }^{\circ} \mathrm{C}$ for $45 \mathrm{~s}, 56^{\circ} \mathrm{C}$ for $30 \mathrm{~s}$ and $72{ }^{\circ} \mathrm{C}$ for $45 \mathrm{~s}$ for 35 cycles, followed by $72{ }^{\circ} \mathrm{C}$ for $10 \mathrm{~min}$. After PCR, $20 \mathrm{uL}$ of each sample were subjected to electrophoresis on $1 \%$ agarose gel. Amplification products were identified according to the expected molecular weight.

\section{Sequencing of DNA and description of alterations}

Each amplicon was purified using QIAquick Gel Extration kit (Qiagen, Hilden, Germany) according to manufacturer's conditions and sequenced using the BigDye Terminator v3.1 cycle sequencing kit and ABI Prism 3130xl Genetic Analyzer sequencer. Sequences were compared with the reference sequence NG_007119 (http://www.ncbi.nih.gov) and confirmed by reverse strand

Table 1 Sequences of primers used in PCR for amplification of the 7 exons of the GLA gene

\begin{tabular}{|c|c|c|}
\hline & Forward primer & Reverse primer \\
\hline 1 & 5'CAGTTGCCAGAGAAACAATAAC3' & 5'CTCTCCAGTTCCCCAAACAC3 ${ }^{\prime}$ \\
\hline 2 & 5'CCCAAGGTGCCTAATAAATG3' & 5'CAAGCTTCTGTACAGAAGTGC $3^{\prime}$ \\
\hline 3 & 5'TGAAGTAACCTTGTCTCTTCC $3^{\prime}$ & 5'GATTGGTTCTTTGGCGCAGC3' \\
\hline 4 & 5'GCCCCAGCTGGAAATTCATTTC ${ }^{\prime}$ & 5'CGTTGGACTTTGAAGGAGACC $3^{\prime}$ \\
\hline 5 & 5'GAGAAGGCTACAAGTGCCTC $3^{\prime}$ & 5'CTCCTCCCAGGAACTTTACC3' \\
\hline 6 & 5'CAGGATGCTGTGGAAAGTGG3' & $5^{\prime}$ CCAAGACAAAGTTGGTATTGGG3 \\
\hline 7 & 5'GGCCACTTATCACTATTTGC3' & 5'TGGAGAAAAAGGTGGACAGG3' \\
\hline
\end{tabular}

sequencing. The alterations were described as suggested in Human Genome Variation Society (HGVS; http://www.hgvs.org/mutnomen/). Residue numbering of the human protein begins with the signal sequence from 1 to 31 amino acids, where the mature GLA protein spans from 32 to 429 amino acids.

\section{Analysis of mutations}

The new missense mutations were analyzed according to the software Polyphen $2^{17}$ (http://genetics.bwh.harvard.edu/pph2) to predict possible impact of an amino-acid alteration on the structure and function of a human protein using straightforward physical and comparative considerations. The alterations were classified as benign, possibly damaging or probably damaging and received a score varying from 0 (benign) to 1 (probably damaging).

\section{GLA activity assays}

The enzymatic diagnosis of affected hemizygotes and heterozygotes was established by determination of the 4-methylumbelliferyl-a-galactosidase A activity in dried blood spots on filter paper and/or leukocytes samples by a fluorometric assay as described for Muller et al., 2010. ${ }^{18}$

\section{RESULTS}

In this study, we analyzed the genomic DNA of 568 Brazilian individuals of 102 families with suspected FD by sequencing the splicing sites in the exon/intron junctions that may cause alternative splicing in gene and the entire coding region of GLA gene in all patients. We found many kinds of alterations in the gene of 222 patients of 51 families, represented by 38 different alterations. From these, 19 were novel mutations and 19 were previously published alterations, according to the Human Gene Mutation Database (http:// www.hgmd.org) (Table 2).

The alterations found in GLA gene were 17 missense mutations, 7 nonsense mutations, 7 deletions, 6 insertions and 1 mutation in splice site. Among the 37 mutations found in the coding region of the GLA gene, only $14(38 \%)$ were identified in exons $1-4$ (encoding residues 1-213), whereas $23(62 \%)$ were found in exons 5-7 (encoding residues 214-429) and among the 13 gene deletions and insertions found, 7 occurred in exons 6 or 7 (54\%). All alterations found are shown in Figure 1.

Except for the insertion c.1129_1130insgCCTGTAATCCT, which elongates four amino acids in the protein sequence, all the other insertions caused a frameshift in the sequence and predicted a truncated protein. Five of the seven identified deletions resulted in the formation of a stop codon. All these changes and the positions of the generated stop codons are identified in Table 2.

Most alterations were detected in only one family with a frequency of $2.6 \%$ among the families with FD, except the alterations A156D, R342Q, R356W, c.1095del1, c.1235_1236del2 that were found at frequency 5.3, 13.2, 15.8, 7.9 and 5.3\%, respectively (Table 2).

In order to determine the impact of the new mutations found in this study, we used the software PolyPhen-2 (http://genetics.bwh. harvard.edu/pph2). This software is able to predict damaging effects of missense mutations. Among the mutations analyzed, the software classified the mutations $\mathrm{A} 15 \mathrm{P}$ and $\mathrm{F} 18 \mathrm{C}$ as benign and scored them as 0.001 and 0.036 , respectively. The mutation W245R was classified as possibly damaging and had a score of 0.677 . The mutations C63Y, A156D, M187T, A292V and I317S were classified as probably damaging and received a score of $0.999,0.988,0.942,0.982$ and 0.996 , respectively.

The GLA activity (affected $<2.5 \mu \mathrm{moll}^{-1}$ of blood per $\mathrm{h}$ in dried blood spots (DBS) on filter paper and $<1.4 \mathrm{nmol} \mathrm{mg}^{-1}$ protein per $\mathrm{h}$ in leukocytes) was evaluated in patients with the mutations A156D, K237X, A292V, I317S and c.1177_1178insG. The mutation A156D caused alteration in the polarity of the amino acid from non-polar to acid polar and was found in a male patient, who presented GLA 
Table 2 Types of alterations in the GLA gene found in genomic DNA of patients with suspected Fabry disease

\begin{tabular}{|c|c|c|c|c|c|c|c|c|}
\hline & $\begin{array}{l}\text { New } \\
\text { (reference) }\end{array}$ & Location & Nucleotide change & Mutation & $\begin{array}{l}\text { Stop } \\
\text { codon }\end{array}$ & $\begin{array}{l}\text { Type of } \\
\text { alteration }\end{array}$ & $\begin{array}{l}\text { No. of } \\
\text { families }\end{array}$ & $\begin{array}{c}\text { Frequency } \\
\text { (\%) }\end{array}$ \\
\hline 1 & No (19) & Intron5 & c. $802-2 A>G$ & & & $\begin{array}{l}\text { Splice } \\
\text { Site }\end{array}$ & 1 & 2.6 \\
\hline 2 & Yes & Exon 1 & c. $43 G>C$ & A15P & & Missense & 1 & 2.6 \\
\hline 3 & Yes & Exon 1 & c. $53 \mathrm{~T}>\mathrm{G}$ & $\mathrm{F} 18 \mathrm{C}$ & & Missense & 1 & 2.6 \\
\hline 4 & No (20) & Exon 1 & c. $141 \mathrm{G}>\mathrm{A}$ & W47X & 47 & Nonsense & 1 & 2.6 \\
\hline 5 & Yes & Exon 1 & c. $189 \mathrm{G}>\mathrm{A}$ & C63Y & & Missense & 1 & 2.6 \\
\hline 6 & No (13) & Exon2 & c. $243 G>A$ & W81X & 81 & Nonsense & 1 & 2.6 \\
\hline 7 & No (21) & Exon2 & c. $335 \mathrm{C}>\mathrm{T}$ & $\mathrm{R} 112 \mathrm{C}$ & & Missense & 1 & 2.6 \\
\hline 8 & No (22) & Exon2 & c. $353 \mathrm{C}>\mathrm{T}$ & R118C & & Missense & 1 & 2.6 \\
\hline 9 & No (23) & Exon3 & c. $425 \mathrm{~T}>\mathrm{C}$ & C142R & & Missense & 1 & 2.6 \\
\hline 10 & Yes & Exon3 & c. $468 \mathrm{C}>\mathrm{A}$ & A156D & & Missense & 2 & 5.3 \\
\hline 11 & Yes & Exon4 & c. $561 \mathrm{~T}>\mathrm{C}$ & M187T & & Missense & 1 & 2.6 \\
\hline 12 & No (24) & Exon5 & c. $659 \mathrm{C}>\mathrm{T}$ & R220X & 220 & Nonsense & 1 & 2.6 \\
\hline 13 & No (25) & Exon5 & c. $678 \mathrm{G}>\mathrm{A}$ & W226X & 226 & Nonsense & 1 & 2.6 \\
\hline 14 & No (26) & Exon5 & c. $680 \mathrm{C}>\mathrm{T}$ & R227X & 227 & Nonsense & 1 & 2.6 \\
\hline 15 & Yes & Exon5 & c. $710 \mathrm{~A}>\mathrm{T}$ & K237X & 237 & Nonsense & 1 & 2.6 \\
\hline 16 & Yes & Exon5 & c. $734 \mathrm{~T}>\mathrm{G}$ & W245R & & Missense & 1 & 2.6 \\
\hline 17 & No (27) & Exon5 & c. $777 \mathrm{C}>\mathrm{G}$ & P259R & & Missense & 1 & 2.6 \\
\hline 18 & No (19) & Exon6 & c. $806 \mathrm{G}>\mathrm{A}$ & V269M & & Missense & 1 & 2.6 \\
\hline 19 & No (28) & Exon6 & c. $852 \mathrm{~T}>\mathrm{C}$ & M284T & & Missense & 1 & 2.6 \\
\hline 20 & Yes & Exon6 & c. $875 \mathrm{C}>\mathrm{T}$ & A292V & & Missense & 1 & 2.6 \\
\hline 21 & Yes & Exon6 & c. $951 \mathrm{~T}>\mathrm{G}$ & I317S & & Missense & 1 & 2.6 \\
\hline 22 & No (29) & Exon7 & c. $1026 \mathrm{G}>\mathrm{A}$ & R342Q & & Missense & 5 & 13.2 \\
\hline 23 & No (30) & Exon7 & c. $1067 C>T$ & R356W & & Missense & 6 & 15.8 \\
\hline 24 & Yes & Exon7 & c. $1102 \mathrm{G}>\mathrm{A}$ & A368W & & Missense & 1 & 2.6 \\
\hline 25 & No (31) & Exon7 & c. $1197 \mathrm{G}>\mathrm{A}$ & W399x & 399 & Nonsense & 1 & 2.6 \\
\hline 26 & Yes & Exon1 & c.73_86insCCCTCGTTTCCTGG & & 103 & Insertion & 1 & 2.6 \\
\hline 27 & Yes & Exon 3 & c. $461 \_462$ insCA & & 165 & Insertion & 1 & 2.6 \\
\hline 28 & Yes & Exon5 & c.733_734insC & & 249 & Insertion & 1 & 2.6 \\
\hline 29 & Yes & Exon7 & c.1078_1079insT & & 374 & Insertion & 1 & 2.6 \\
\hline 30 & Yes & Exon7 & c.1129_1130insGCCTGTAATCCT & & & Insertion & 1 & 2.6 \\
\hline 31 & Yes & Exon7 & c.1177_1178insG & & 418 & Insertion & 1 & 2.6 \\
\hline 32 & No (19) & Exon1 & c.33del1 & & 120 & Deletion & 1 & 2.6 \\
\hline 33 & Yes & Exon 3 & c.469_470del2 & & 160 & Deletion & 1 & 2.6 \\
\hline 34 & No (25) & Exon 5 & c.718_719del2 & & 248 & Deletion & 1 & 2.6 \\
\hline 35 & Yes & Exon6 & c.941_961del21 & & & Deletion & 1 & 2.6 \\
\hline 36 & Yes & Exon6 & c.995_998del4 & & 349 & Deletion & 1 & 2.6 \\
\hline 37 & No (20) & Exon7 & c.1095del1 & & 365 & Deletion & 3 & 7.9 \\
\hline 38 & No (32) & Exon7 & c.1235_1236del2 & & & Deletion & 2 & 5.3 \\
\hline
\end{tabular}

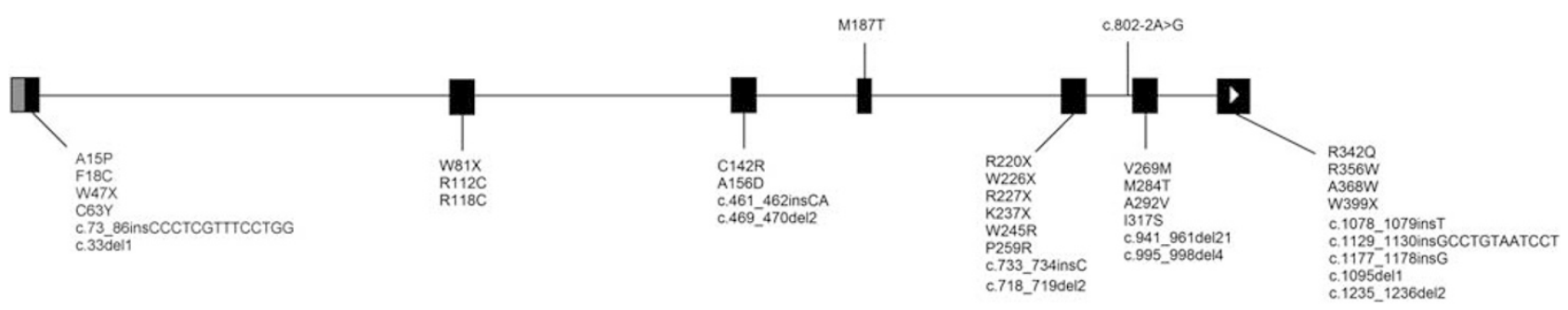

Figure 1 Map of the GLA gene with the seven exons and alterations found in patients with suspect of FD.

activity of $1.36 \mu \mathrm{moll}^{-1}$ of blood per h in DBS and activity not detected in leukocytes. The mutation K237X removed 192 amino acids of the GLA and was found in a female patient with GLA activity of $0.68 \mu \mathrm{moll}^{-1}$ of blood per h in DBS and $1.63 \mathrm{nmol} \mathrm{mg}^{-1}$ protein per $\mathrm{h}$ in leukocytes. The A292V mutation did not alter the polarity of the amino acid and was found in two men with GLA activity of $0.54 \mu \mathrm{moll}^{-1}$ of blood per $\mathrm{h}$ in DBS and $0.19 \mathrm{nmol} \mathrm{mg}^{-1}$ protein per $\mathrm{h}$ in leukocytes and $1.33 \mu \mathrm{moll}^{-1}$ of blood per h in DBS and not detected in leukocytes. The mutation I317S caused alteration in the polarity of amino acid from non-polar to neutral polar and was found in nine 
Table 3 Correlations of new mutations found in the GLA gene with prediction of molecular damage and enzymatic activity in the Fabry patients

\begin{tabular}{|c|c|c|c|c|}
\hline \multirow[b]{2}{*}{ Mutation } & \multirow[b]{2}{*}{ Gender } & \multirow[b]{2}{*}{ Score ${ }^{a}$} & \multicolumn{2}{|c|}{ Enzymatic activity } \\
\hline & & & $D B S$ & $L$ \\
\hline A156D & $M$ & 0.988 (PD) & 1.36 & ND \\
\hline K237X & $\mathrm{F}$ & - & 0.68 & 1.63 \\
\hline A292V & $\mathrm{M} / \mathrm{M}$ & 0.982 (PD) & $0.54 / 1.33$ & $0.19 / \mathrm{ND}$ \\
\hline $1317 \mathrm{~S}$ & M & 0.996 (PD) & ND & 0.77 \\
\hline c.1177_1178insG & M & - & NA & ND \\
\hline
\end{tabular}

Abbreviations: DBS, dried blood spots on filter paper (affected $<2.5 \mu \mathrm{mol} \mathrm{I}^{-1}$ of blood per $\mathrm{h}$ ); $\mathrm{L}$, leukocytes (affected $<1.4 \mathrm{nmol} \mathrm{mg}^{-1}$ protein per h); NA, not available; ND, not detected; PD, probably damaging. $\mathrm{M} / \mathrm{M}$ indicates that the two patients are male.

The alterations were classified as benign, possibly damaging or probably damaging and received a score varying from 0 (benign) to 1 (probably damaging).

women and one man of the same family. The enzyme activity was measured in the male patient and was not detected in DBS and was $0.77 \mathrm{nmol} \mathrm{mg}^{-1}$ protein per $\mathrm{h}$ in leukocytes. The c.1177_1178insG was detected in one man with an activity of $1.0 \mathrm{nmol}$ $\mathrm{mg}^{-1}$ protein per $\mathrm{h}$ in leukocytes. This mutation caused truncation at the end of the enzyme sequence (418 residues), affecting the activity of GLA and triggering FD phenotype.

The clinical symptoms, enzymatic activity and software prediction presented in Table 3 suggest that the five mutations are likely the cause of the manifestations of FD, as no further changes were found in the coding region and in the splicing sites of the GLA gene.

\section{DISCUSSION}

In this study, 102 Brazilian families with 568 individuals susceptible for FD were analyzed and 222 patients had alterations in the GLA gene. This work describes the first comprehensive molecular analysis of the GLA gene in a cohort of 568 Brazilian individuals in 102 families with suspect of FD. We detected 222 patients of 51 families with molecular alterations. The GLA gene has $>600$ mutations described and this study identified 38 alterations, of which 19 (50\%) were not previously reported in the literature. The alterations were dispersed along the gene and the majority were missense mutations.

Five alterations occurred by $\mathrm{C}>\mathrm{T}$ alteration in the first base at $\mathrm{CpG}$ dinucleotides (R112C, R118C, R220X, R227X and R356W), and one occurred by alteration $\mathrm{G}>\mathrm{A}$ in the second base (R342Q) at $\mathrm{CpG}$ dinucleotides. The missense mutations $\mathrm{R} 342 \mathrm{Q}$ and $\mathrm{R} 356 \mathrm{~W}$ in the coding region were the most frequent, appearing in five and six families, respectively. This high frequency is probably because both mutations are in $\mathrm{CpG}$ dinucleotides, known hotspots for mutation. ${ }^{33,34}$ These findings are consistent with the study of methylation of DNA within the coding region that may contribute significantly to the incidence of human genetic disease. ${ }^{35}$ In addition, genes on the $\mathrm{X}$-chromosome may be more susceptible to $\mathrm{C}>\mathrm{T}$ transitions, as methylation and demethylation of certain $\mathrm{CpG}$ dinucleotides appear to be important for maintaining X-inactivation in females. ${ }^{36-38}$ The mutations in nucleotides 112 and 227 of GLA are the most frequently involving $\mathrm{CpG}$ dinucleotides ${ }^{39}$ and in the Brazilian patients it was found one family with mutation in nucleotide 112 (R112C) and one to nucleotide 227 (R227X).

Among the 13 deletions and insertions in the coding region of GLA found in our study, seven occurred in exons 6 or 7 (54\%), suggesting that this region is prone to small gene rearrangements. ${ }^{27,31}$
In order to maintain the enzymatic activity, it is necessary to have both domains of GLA intact. Although domain 2 does not contribute to the active site, it must remain integral to the proper folding of the GLA dimer. ${ }^{40}$ So, it is not surprising that the new insertions and deletions as c.73_86insCCCTCGTTTCCTGG, c.461_462insCA, c.733_734insC, c.1078_1079insT, c.33del1, c.469_470del2, c.718_ 719del2, c.995_998del4 and c.1095del1, that caused a stop codon and removed a portion of the GLA domain, may trigger FD.

The c.941_961del21 produced a GLA protein lacking seven amino acids (from amino acid 315 to 321). Studies in this region of the protein showed that the amino acid 320 is buried (i.e., those with $<2 \AA^{2}$ accessible surface area per side chain atom). In general, mutations causing the severe phenotype of FD tend to be in amino acids buried in the interior of the GLA, whereas mutations causing the mild phenotype tend to be less disruptive to the hydrophobic core of the protein. ${ }^{40}$ Thus, this deletion probably altered the tertiary structure and/or function of the protein that explains the clinical manifestations of FD. Interestingly, the rearrangement c.1129_ 1130insGCCTGTAATCCT also did not cause a stop codon, but on the other hand promoted an increase in the sequence of GLA. This alteration also changed the tertiary structure and/or function of the protein, reducing the activity of GLA and causing FD. More studies with crystallography of X-ray could show how this alteration influences the structure of GLA.

An $A>G$ alteration in the genomic sequence was identified at position -2 bp before the beginning of exon 6 . This splice site singlebase alteration is located at the $5^{\prime}$ receptor consensus splice site of intron 5 (c.802-2 $A>G)$, which is predicted to result in aberrant mRNA processing ${ }^{19}$ and a female patient with this mutation presented low enzymatic activity. This mutation is located at the splicing site and probably leads to the expression of aberrant forms of messenger RNA, which could explain the symptoms of FD.

In summary, this is a comprehensive study of genomic alterations in FD. Our findings show a very long list of alterations distributed along the GLA gene in Brazilian families. There are few molecular studies describing genetic alterations in FD in Brazil. In 1999, AshtonProla and cols described the first mutation in FD in a Brazilian family (30delG). ${ }^{41}$ Eight years later, Pereira and cols (2007) analyzed 6 male and 7 female individuals belonging to 4 different FD families. In this study the authors described four mutations (30delG, 1033delTC, W349X and L36F). ${ }^{42}$ Therefore, our data show the analysis of a much higher number of FD individuals and families. The data show the extensive molecular genetics heterogeneity in this disease and support the fact that many of the GLA mutations causing FD are familyspecific. This analysis is important for each patient with FD, because the detection of these mutations could help in the identification of potential candidates for recombinant enzyme-replacement treatment and will permit precise diagnosis of the heterozygous carriers of this $\mathrm{X}$-linked gene. We believe that in the future, when a clear genotypephenotype correlation for FD is very well established, this kind of information will be extremely relevant for the treatment of the patient. Furthermore, a precise molecular analysis will bring better understanding of each change in the GLA gene and will improve genetic counseling.

\section{ACKNOWLEDGEMENTS}

This work was supported by grants from FAPESP (2008/06676-8). VD'A and JBP are recipients from fellowships from CNPq, Brazil. We would like to thank all the physicians that helped the accomplishment of this work, providing the samples analyzed in this work. 
1 Desnick, R. J., Ioannou, Y. A. \& Eng, C. M. Alpha-Galactosidase A deficiency: Fabry disease. in The Metabolic and Molecular Bases of Inherited Disease (Springer, New York (2001).

2 Schiffmann, R. Fabry disease. Pharmacol. Ther. 122, 65-77 (2009).

3 Meikle, P. J., Hopwood, J. J., Clague, A. E. \& Carey, W. F. Prevalence of lysosomal storage disorders. Jama 281, 249-254 (1999).

4 Scriver, C. R., Beaudet, A. L., Sly, W. S., Valle, D., Childs, B., Kinzler et al. The Metabolic and Molecular Bases of Inherited Disease (McGraw-Hill, New York, 2002).

5 Puck, J. M. \& Willard, H. F. X inactivation in females with X-linked disease. N. Engl. J. Med. 338, 325-328 (1998).

6 Desnick, R. J. \& Sweeley, C. C. Fabry's disease: defective a-galactosidase A. in The Metabolic Basis of Inherited Disease (McGraw-Hill, New York, 1984).

7 Lyon, M. F. Gene action in the X-chromosome of the mouse (Mus musculus L.). Nature 190, 372-373 (1961)

8 Guffon, N. Clinical presentation in female patients with Fabry disease. J. Med. Genet. 40, e38 (2003)

9 Whybra, C., Kampmann, C., Willers, I, Davies, J., Winchester, B., Kriegsmann, J. et al. Anderson-Fabry disease: clinical manifestations of disease in female heterozygotes J. Inherit. Metab. Dis. 24, 715-724 (2001).

10 Eng, C. M., Banikazemi, M., Gordon, R. E., Goldman, M., Phelps, R., Kim, L. et al. A phase $1 / 2$ clinical trial of enzyme replacement in fabry disease: pharmacokinetic, substrate clearance, and safety studies. Am. J. Hum. Genet. 68, 711-722 (2001).

11 Eng, C. M., Guffon, N., Wilcox, W. R., Germain, D. P., Lee, P., Waldek, S. et al. Safety and efficacy of recombinant human alpha-galactosidase A-replacement therapy in Fabry's disease. N. Engl. J. Med. 345, 9-16 (2001).

12 Schiffmann, R., Kopp, J. B., Austin, 3rd H. A., Sabnis, S., Moore, D. F., Weibel, T. et al. Enzyme replacement therapy in Fabry disease: a randomized controlled trial. Jama 285, 2743-2749 (2001).

13 Eng, C. M., Niehaus, D. J., Enriquez, A. L., Burgert, T. S., Ludman, M. D. \& Desnick, R. J. Fabry disease: twenty-three mutations including sense and antisense $C p G$ alterations and identification of a deletional hot-spot in the alpha-galactosidase $A$ gene. Hum. Mol. Genet. 3, 1795-1799 (1994).

14 Kornreich, R., Desnick, R. J. \& Bishop, D. F. Nucleotide sequence of the human alphagalactosidase A gene. Nucleic Acids Res. 17, 3301-3302 (1989).

15 Bishop, D. F., Calhoun, D. H., Bernstein, H. S., Hantzopoulos, P., Quinn, M. \& Desnick, R. J. Human alpha-galactosidase A: nucleotide sequence of a cDNA clone encoding the mature enzyme. Proc. Natl Acad. Sci. USA 83, 4859-4863 (1986).

16 Bishop, D. F., Kornreich, R. \& Desnick, R. J. Structural organization of the human alpha-galactosidase A gene: further evidence for the absence of a $3^{\prime}$ untranslated region. Proc. Natl Acad. Sci. USA 85, 3903-3907 (1988).

17 Adzhubei, I. A., Schmidt, S., Peshkin, L., Ramensky, V. E., Gerasimova, A., Bork, P. et al. A method and server for predicting damaging missense mutations. Nat. Methods 7, 248-249 (2010).

18 Müller, K. B., Rodrigues, M. D. B., Pereira, V. G., Martins, A. M. \& D'Almeida, V. Reference values for lysosomal enzymes activities using dried blood spots samples - a Brazilian experience. Diagn. Pathol. 5, 65 (2010).

19 Shabbeer, J., Yasuda, M., Benson, S. D. \& Desnick, R. J. Fabry disease: identification of 50 novel alpha-galactosidase A mutations causing the classic phenotype and threedimensional structural analysis of 29 missense mutations. Hum. Genomics. 2, 297-309 (2006).

20 Batista, E. C., Carvalho, L. R., Casarini, D. E., Carmona, A. K., dos Santos, E. L., da Silva, E. D. et al. ACE activity is modulated by the enzyme alpha-galactosidase A. J. Mol. Med. (Berl) 89, 65-74 (2011)

21 Ishii, S., Sakuraba, H. \& Suzuki, Y. Point mutations in the upstream region of the alpha-galactosidase A gene exon 6 in an atypical variant of Fabry disease. Hum. Genet. 89, 29-32 (1992)
22 Spada, M., Pagliardini, S., Yasuda, M., Tukel, T., Thiagarajan, G., Sakuraba, H. et al. High incidence of later-onset fabry disease revealed by newborn screening. Am. J. Hum. Genet. 79, 31-40 (2006).

23 Okumiya, T., Ishii, S., Kase, R., Kamei, S., Sakuraba, H. \& Suzuki, Y. Alphagalactosidase gene mutations in Fabry disease: heterogeneous expressions of mutant enzyme proteins. Hum. Genet. 95, 557-561 (1995).

24 Meaney, C., Blanch, L. C. \& Morris, C. P. A nonsense mutation (R220X) in the alphagalactosidase A gene detected in a female carrier of Fabry disease. Hum. Mol. Genet. 3, 1019-1020 (1994).

25 Davies, J., Christomanou, H., Winchester, B. \& Malcolm, S. Detection of 8 new mutations in the alpha-galactosidase A gene in Fabry disease. Hum. Mol. Genet. 3, 667-669 (1994).

26 Davies, J. P., Winchester, B. G. \& Malcolm, S. Mutation analysis in patients with the typical form of Anderson-Fabry disease. Hum. Mol. Genet. 2, 1051-3 (1993).

27 Ashley, G. A., Shabbeer, J., Yasuda, M., Eng, C. M. \& Desnick, R. J. Fabry disease: twenty novel alpha-galactosidase A mutations causing the classical phenotype. J. Hum. Genet. 46, 192-196 (2001).

28 Blanch, L. C., Meaney, C. \& Morris, C. P. A sensitive mutation screening strategy for Fabry disease: detection of nine mutations in the alpha-galactosidase A gene. Hum. Mutat. 8, 38-43 (1996).

29 Ploos van Amstel, J. K., Jansen, R. P., de Jong, J. G., Hamel, B. C. \& Wevers, R. A. Six novel mutations in the alpha-galactosidase $A$ gene in families with Fabry disease. Hum. Mol. Genet. 3, 503-505 (1994).

30 Bernstein, H. S., Bishop, D. F., Astrin, K. H., Kornreich, R., Eng, C. M., Sakuraba, H. et al. Fabry disease: six gene rearrangements and an exonic point mutation in the alpha-galactosidase gene. J. Clin. Invest. 83, 1390-1399 (1989).

31 Eng, C. M., Ashley, G. A., Burgert, T. S., Enriquez, A. L., D'Souza, M. \& Desnick, R. J. Fabry disease: thirty-five mutations in the alpha-galactosidase $A$ gene in patients with classic and variant phenotypes. Mol. Med. 3, 174-182 (1997).

32 Blaydon, D., Hill, J. \& Winchester, B. Fabry disease: 20 novel GLA mutations in 35 families. Hum. Mutat. 18, 459 (2001).

33 Barker, D., Schafer, M. \& White, R. Restriction sites containing CpG show a higher frequency of polymorphism in human DNA. Cell 36, 131-138 (1984).

34 Gan, J., Zhang, Y. L., Carter, K. B., Cauthron, R. D. \& Steinberg, R. A. On the spontaneous mutability of $\mathrm{CpG}$ sites in cultured S49 mouse lymphoma cells. Somat. Cell. Mol. Genet. 25, 129-145 (1999).

35 Cooper, D. N. \& Youssoufian, H. The CpG dinucleotide and human genetic disease. Hum. Genet. 78, 151-155 (1988).

36 Cullen, C. R., Hubberman, P., Kaslow, D. C. \& Migeon, B. R. Comparison of factor IX methylation on human active and inactive $X$ chromosomes: implications for $X$ inactivation and transcription of tissue-specific genes. EMBO J. 5, 2223-2229 (1986).

37 Gartler, S. M. \& Riggs, A. D. Mammalian X-chromosome inactivation. Annu. Rev. Genet. 17, 155-190 (1983).

38 Yen, P. H., Patel, P., Chinault, A. C., Mohandas, T. \& Shapiro, L. J. Differential methylation of hypoxanthine phosphoribosyltransferase genes on active and inactive human X chromosomes. Proc. Natl. Acad. Sci. USA 81, 1759-1763 (1984).

39 Shabbeer, J., Yasuda, M., Luca, E. \& Desnick, R. J. Fabry disease: 45 novel mutations in the alpha-galactosidase A gene causing the classical phenotype. Mol. Genet. Metab. 76, 23-30 (2002).

40 Garman, S. C. \& Garboczi, D. N. Structural basis of Fabry disease. Mol. Genet. Metab. 77, 3-11 (2002).

41 Ashton-Prolla, P., Ashley, G. A., Giugliani, R., Pires, R. F., Desnick, R. J. \& Eng, C. M. Fabry disease: comparison of enzymatic, linkage, and mutation analysis for carrier detection in a family with a novel mutation (30delG). Am. J. Med. Genet. 84, 420-424 (1999).

42 Pereira, F. S., Jardim, L. B., Netto, C. B., Burin, M. G., Cecchin, C., Giugliani, R. et al. Genomic analysis of Brazilian patients with Fabry disease. Braz. J. Med. Biol. Res. 40, 1599-1604 (2007). 